\title{
UMA NOVA ABORDAGEM EMPÍRICA PARA A HIERARQUIA DE STATUS NO BRASIL
}

\author{
André Ricardo Salata
}

Pontifícia Universidade Católica do Rio Grande do Sul (PUCRS), Porto Alegre - RS. E-mail: andre.salata@pucrs.br

DOI: $10.17666 / 319203 / 2016$

\section{Introdução}

Uma das características principais da abordagem weberiana sobre as desigualdades, que a distingue da perspectiva marxista (Scalon, 1999; Grusky, 2008), é o reconhecimento de múltiplas dimensóes através das quais esse fenômeno se estrutura. Enquanto que, para Marx, as desigualdades na sociedade moderna se estruturariam essencialmente através das classes, em Weber encontramos a possibilidade de a sociedade estratificar-se também por status. ${ }^{1}$ Trata-se, portanto, de uma abordagem multidimensional da estratificação social. ${ }^{2}$

Apesar de ser esta uma concepção fundamental, e bastante conhecida, na obra de Weber, infelizmente nas últimas décadas pouca atenção tem sido dada à mesma, de modo que os estudos sobre

Artigo recebido em 08/02/2015

Aprovado em 16/02/2016 o tema - mesmo entre aqueles autores considerados weberianos - têm conferido primazia à estratificação por classes (Wright, 1989; Goldthorpe, 2000), ou, mesmo quando trazem a ideia de status para seu campo de análise, o fazem distorcendo seu significado (Blau e Duncan, 1967; Treiman, 1977), ou então procurando reduzi-la a um epifenômeno da divisão por classes (Bourdieu, 2008).

A importância de incorporarmos, de modo mais sistemático e profundo, a dimensão do status às pesquisas sobre estratificação tem sido lembrada por autores como Scott (1994) e Devine e Savage (2005). Recentes estudos têm inclusive procurado explorar os diferentes mecanismos através dos quais as hierarquias de status exerceriam efeito direto sobre a produção e reprodução das desigualdades sociais (Ridgeway, 2013). Nesse sentido, torna-se imprescindível contarmos com ferramentas adequadas para a sua mensuração. Somente nos últimos anos, no entanto, é que uma nova aborda- 
gem metodológica vem sendo desenvolvida (Chan e Goldthorpe, 2004, 2007), buscando resgatar a ideia de status, seu significado original - conforme encontrado nos textos de Weber -, e sua distinção analítica em relação à estratificação por classes, possibilitando assim que essa dimensão seja tomada como objeto de análise de modo mais adequado.

Neste artigo, iremos aplicar essa nova abordagem para o Brasil, buscando verificar se podemos encontrar uma ordem de status bem definida no país, e quais seriam suas características e propriedades. Basicamente, seguindo os passos indicados por Chan e Goldhorpe (2004, 2007), desenvolveremos uma nova escala de status para o Brasil mediante as informações ocupacionais dos microdados da Pesquisa Nacional por Amostra de Domicílios (PNAD) de 2013.

O desenvolvimento dessa escala é interessante não apenas pelas possibilidades de análise que a mesma tornaria possível, como já tem acontecido em outros países como Reino Unido, Chile, Hungria e Estados Unidos (Chan, 2010), mas também pelo fato de grande parte da literatura sobre o Brasil tomá-lo como uma sociedade bastante hierarquizada do ponto de vista social (Matta, 1979; Freyre, 1961, 1936; Fernandes, 2009; Souza, 2006). Será que poderíamos encontrar, então, uma substantiva hierarquia de status no Brasil? Se sim, como esta se estrutura? Quais categorias se encontram na parte superior e inferior dessa hierarquia? Ela se relaciona com características como escolaridade, rendimentos e/ou situação de classe? De que modo? Essas são as principais questóes às quais pretendemos oferecer respostas no decorrer do texto.

Após a exposição detalhada da definição de status social em Weber, suas principais características, e a distinção em relação à ideia de classes, realizamos uma pequena revisão dos mais importantes trabalhos que já procuraram mensurar essa dimensão da estratificação. Posteriormente, apresentamos a construção de uma nova escala de status social para o Brasil, utilizando dados da PNAD de 2013, e analisamos essa escala para verificar suas propriedades e a validade de sua interpretação como uma escala de status. Por fim, relatamos as principais conclusōes alcançadas e apontamos os próximos passos de nossa agenda de pesquisa.

\section{Status e sua mensuração}

Max Weber costumava tratar a estratificação como produto da repartiçáo de poder em uma sociedade. A estratificação por classes, nesse sentido, seria um fenômeno da distribuição de poder econômico e categorizaria os indivíduos de acordo com os recursos que estes possuem a fim de obter retornos no mercado. Poderíamos, assim, falar de grandes proprietários, pequenos proprietários, trabalhadores qualificados, trabalhadores não qualificados etc., como distintas classes, cada uma agregando indivíduos com diferentes chances e oportunidades econômicas.

À essa primeira dimensão da estratificação, por classes, Weber acrescenta uma segunda dimensão, a do status. Diferentemente da primeira, a estratificação por status não diria respeito à distribuição de poder econômico, mas sim de poder social. Trata-se, aqui, da distribuição de prestígio e/ou honra, em uma comunidade, que esteja relacionada com alguma(s) característica(s) compartilhada(s) por uma pluralidade de indivíduos. Tais características poderiam ser adscritas, como cor, gênero, idade e origem social, ou então alcançadas, como escolaridade, ocupação e rendimentos.

A estratificação por status, que, segundo Weber, teria como fundamento a distribuição de prestígio, seria identificável principalmente pelos diferentes estilos de vida e pelas redes de relaçóes sociais, em especial as relaçóes mais íntimas, como amizade e matrimônio. Normalmente, pessoas de status social mais elevado tenderiam a se relacionar com outras pessoas de status também elevado, restringindo o contato com indivíduos de menor prestígio social. Indivíduos de menor status, por sua vez, apresentariam a tendência de se relacionar com outras pessoas também de baixo status, sendo limitado o seu acesso aos círculos mais íntimos dos grupos de prestígio social elevado. ${ }^{3}$ Por meio dessas práticas, então, como estilos de vida distintos e restriçóes às relações mais íntimas, os grupos sociais buscariam exercer e afirmar sua posição social superior. ${ }^{4}$

Tais escalas de poder e/ou reconhecimento social adquirem tons mais claros em determinados contextos sociais e históricos. Nas chamadas sociedades modernas, dado o desenvolvimento da ideia 
de igualdade básica entre os indivíduos (Marshall, 1950), essa hierarquia tenderia a se tornar menos visível, e até mesmo reprovável. De todo modo, mesmo que de maneira menos declarada - mas passível de ser atestada - ocorrem hierarquias de status, como desigualdades de honra e/ou reconhecimento social, até em países economicamente mais avançados (Chan, 2010).

É importante lembrar que, antes de Weber, outros autores já haviam estabelecido, de algum modo, distinções relacionadas com a separação entre classe e status. Seria o caso da conhecida diferenciação elaborada por Tönnies (1953 [1931]) entre Gemeinschaft e Gesellschaft. ${ }^{5}$ Nessa perspectiva, a estratificação por status e a estratificação por classes eram tomadas como representativas de dois momentos distintos em uma dada ordem cronológica que descreveria a passagem da sociedade tradicional para a sociedade moderna. Uma das grandes contribuiçôes de Weber, então, para os estudos sobre estratificação social, foi tomar classe e status como duas dimensóes da divisão do poder que tipicamente coexistem em uma sociedade, podendo, é claro, assumir maior ou menor relevância em determinados contextos históricos. ${ }^{6}$

Como dissemos, graças ao desenvolvimento da ideia de uma igualdade básica entre os indivíduos, atrelada à construção da cidadania, nas sociedades modernas a estratificação por classes tende a se tornar mais relevante em relação à estratificação por status, abrandando assim diferenciais de honra e prestígio social - às quais muitas vezes estavam associados direito e deveres específicos. A relação entre classe e status, no entanto, como duas dimensôes distintas da estratificação que podem ou não se reforçar mutuamente, continua existindo mesmo em sociedades que lograram disseminar a noção de cidadania. O caráter dessa relaçáo, e o peso de uma ou outra dimensão, entretanto, podem variar bastante, assumindo diversas formas em diferentes sociedades.

A separação elaborada por Weber entre classe e status, portanto, seria apenas analítica e conceitual, já que na realidade essas duas dimensōes da estratificação estariam comumente relacionadas, exercendo influência uma sobre a outra. O reconhecimento dessa distinção possibilita ao pesquisador analisar separadamente cada uma daquelas dimensóes da estratificação, assim como suas causas, processos e consequências típicas. Possibilita, também, tomar como variável, de acordo com o contexto histórico investigado, o princípio de estratificação dominante em uma determinada sociedade. Por fim, permite ainda o exame das diversas maneiras através das quais classe e status podem estar relacionados, influenciando-se mutuamente. Bourdieu (2008), por exemplo, em $A$ distinção, procura analisar como essas duas dimensóes se reforçavam mutuamente na sociedade francesa do século XX.

Para que essas possibilidades, abertas pela distinção conceitual elaborada por Weber, sejam aproveitadas, é necessário contarmos com instrumentos empíricos capazes de fornecer informaçóes a respeito daquelas diferentes dimensóes da estratificação. Quanto à dimensão econômica, nas últimas décadas podemos notar uma série de estudos que colaboraram para o desenvolvimento dos já conhecidos esquemas de classe, sendo os de Goldthorpe (2000) e Wright (1989) os mais utilizados. No Brasil, estudos como os de Scalon (1999), Silva (2003), Ribeiro (2006), Santos (2008) e Preteceille e Ribeiro (1999), entre muitos outros, também têm feito uso dos esquemas de classe, construídos através das informações ocupacionais, a fim de tratar questôes como mobilidade social, desigualdades de rendimentos, padrōes de segmentação socioespacial etc. ${ }^{7}$ Já no que diz respeito à dimensão social, conforme veremos a seguir, acreditamos que somente nos últimos anos é que uma medida realmente indicadora de status, respeitando o significado atribuído por Weber ao termo, assim como a separaçâo analítica em relação à dimensão econômica, vem sendo desenvolvida.

\section{Escalas de prestígio elou status socioeconômico}

Trabalhos empíricos sobre status não são novidade no campo de estudos sobre estratificação e desigualdades sociais. Apesar de, nas últimas décadas, os trabalhos a respeito de classes e suas consequências - em termos de rendimentos, desempenho escolar etc. - terem predominado, é marcante a presença também de trabalhos utilizando as chamadas escalas de prestígio e/ou status, como o SEI (Socioeconomic Index), a Siops (Internationally Comparable Measures of Occupational Status) e 
o Isei (International Socioeconomic Index). Ao contrário da escala que desenvolveremos aqui, entretanto, acreditamos que tais escalas não representariam adequadamente aquilo que Weber definira como status social, por razóes que procuramos expor nos próximos parágrafos.

Apesar de algumas variações, os estudos que visavam medir prestígio ocupacional procediam da seguinte maneira: uma amostra da população era solicitada a ranquear, ou atribuir valores, a um número limitado de ocupaçóes - de acordo com o prestígio atribuído pelo entrevistado às mesmas. Esses scores eram então agregados em valores médios e tratados como indicadores de prestígio relativo das categorias avaliadas. ${ }^{8}$

O principal problema desse tipo de escala, no entanto, é que as informaçóes de prestígio eram normalmente obtidas apenas para um pequeno número de categorias ocupacionais.

Visando contornar esse problema, Blau e Duncan (1967) desenvolveram um índice socioeconômico de status ocupacional, concebido para reproduzir os scores de prestígio, da maneira mais fiel possível, para um conjunto mais amplo de ocupaçôes. Com esse intuito, utilizaram as pontuações de prestígio obtidas a partir de uma amostra, onde podiam ser calculados scores de prestígio para 45 ocupaçóes cujos títulos eram muito semelhantes àqueles do censo. Utilizando também a base de dados do censo de 1950, os autores criaram duas variáveis, indicadoras de escolaridade e rendimentos, com informaçóes agregadas para cada uma daquelas 45 categorias ocupacionais.

Posteriormente, Blau e Duncan rodaram uma regressão linear múltipla, tendo a variável indicadora de prestígio como dependente, e as informaçóes de escolaridade e rendimentos como independentes. Utilizando os coeficientes dessa regressão, para escolaridade e renda, como pesos, foi então possível atribuir scores para todas as ocupaçóes do censo. Ao final do processo, era gerada uma escala cujos valores podiam ser interpretados como estimadores de prestígio, ou, simplesmente, como uma escala de status socioeconômico.

Escalas de prestígio e de status socioeconômico são semelhantes por serem medidas contínuas e unidimensionais ${ }^{9}$ da estratificação em uma socie- dade. Entretanto, elas são construídas, e devem ser assim interpretadas, de modos distintos.

A escala de status socioeconômico mais utilizada, por exemplo, o Isei, foi construída visando maximizar a relação com renda e escolaridade, sem qualquer ligação com julgamentos subjetivos de prestígio (Ganzeboom, De Graaf e Treiman, 1992). O Isei foi desenvolvido para mensurar os atributos das ocupaçóes que convertem a educação em rendimentos. As ocupaçóes foram então tomadas como mecanismos que convertem o principal recurso dos indivíduos, a educação, em renda. Destarte, trata-se de uma medida que minimiza o efeito direto e maximiza o efeito indireto (através da ocupaçáo) da escolaridade sobre os rendimentos.

Tais escalas têm sido utilizadas em muitos países, inclusive no Brasil. Marques, Scalon e Oliveira (2008), por exemplo, utilizaram o Isei em um interessante estudo sobre a estrutura social das duas maiores metrópoles brasileiras: Rio de Janeiro e São Paulo. Mais do que isso, em um conhecido trabalho, Nelson Valle Silva (1974) construiu uma escala de status socioeconômico a partir de dados nacionais para o Brasil. Para tanto, adotou também como critério informaçóes relativas a escolaridade e rendimentos dos indivíduos que compunham as categorias ocupacionais.

Do ponto de vista operacional, essas escalas se mostram muito convenientes, pois com uma única variável contínua é possível resumir as informaçóes socioeconômicas, facilitando a aplicação de técnicas mais simples de análise de dados - como realizado por Blau e Duncan (1967) em seu conhecido estudo sobre mobilidade social: The American occupational structure. Mas, ao mesmo tempo, reunir informaçóes de educação, renda e - às vezes - prestígio numa única escala seria também o seu maior problema, já que tornaria impossível o estudo em separado das diferentes dimensōes da estratificação social. Além disso, mesmo aquelas escalas computadas para um menor número de ocupaçóes, apesar de serem muitas vezes interpretadas como scores de prestígio, na verdade parecem indicar o grau em que certas ocupaçóes são desejadas - em virtude de características como remuneração e habilidades requeridas (Goldthorpe e Hope, 1972).

Desse modo, apesar do grande uso que tem sido feito dessas chamadas escalas de prestígio e/ou 
status socioeconômico, em grande medida fruto da praticidade em utilizar variáveis contínuas nas análises estatísticas, acreditamos que não seria correto interpretar as informações resumidas nessas escalas como indicadoras daquilo que Weber entendia como status: a dimensão social da estratificação. ${ }^{10}$

Status como distância social

A partir de outra perspectiva, pesquisadores de Cambridge vêm, há algumas décadas, desenvolvendo uma escala de distâncias sociais. Foi o trabalho desses pesquisadores que deu origem à escala de status elaborada mais recentemente por Chan e Goldthorpe (2004, 2007), também no Reino Unido, que tomaremos como referência para o presente estudo.

A ideia principal por trás da escala de Cambridge é utilizar padróes de associação a fim de mensurar hierarquias sociais. Trabalhos anteriores já haviam procurado seguir esse caminho (Warner e Lunt, 1942), porém utilizando técnicas de análise bastante limitadas. ${ }^{11}$ Foi somente a partir da pesquisa de Laumann e Guttman (1966) que resultados mais promissores começaram a ser alcançados, de modo que, em 1973, Stewart, Prandy e Blackburn realizaram a primeira publicação da Cambridge Scale. ${ }^{12}$

A ideia básica para a construção e interpretação dessa escala é a de que os membros da sociedade possuem uma noção do lugar que eles, e também terceiros, ocupam no espaço social, e que tendem a interagir, de modo socialmente significativo - ou seja, no que diz respeito às relaçóes mais íntimas -, com aqueles que consideram próximos. Por outro lado, certos grupos procurariam evitar estabelecer esse tipo de relaçóes com quem consideram distantes. Desse modo, ao estudar os padróes de relaçóes íntimas seria possível captar as hierarquias presentes na sociedade.

Do ponto de vista operacional, a escala de Cambridge é derivada do cruzamento entre as ocupaçōes dos indivíduos com aquelas de seu(s) amigo(s) mais próximo(s), parentes e/ou cônjuges. ${ }^{13}$ Essas informaçôes cruzadas são, então, submetidas à técnica de multidimensional scalling, através da qual uma escala de distâncias sociais é extraída. ${ }^{14}$ Os resultados obtidos revelam similaridades e diferenças entre categorias ocupacionais, que devem ser tomadas como indicadores de menor ou maior grau de distância social.
A ideia, portanto, é tornar visível a natureza do espaço social, definido pelas distâncias que o compóem.

Autores como Prandy e Lambert (2003) interpretam a escala de Cambridge como reflexo de desigualdades - vantagens e desvantagens - materiais e sociais combinadas. A escala, desse modo, possibilitaria o estudo da reprodução das desigualdades totais, num processo em que as dimensóes sociais e econômicas seriam inseparáveis. Chan e Goldthorpe (2004, 2007), por sua vez, ao fazerem uso da abordagem desenvolvida pelo grupo de Cambridge, argumentam que seus resultados permitiriam a identificação das hierarquias de status. Portanto, apesar de a metodologia empregada pelos últimos ser praticamente a mesma daquela utilizada para o desenvolvimento da Camsis (Cambridge Social Interaction and Stratification Scales), sua interpretação dos resultados é bastante distinta, já que os toma como indicadores apenas de status social, trabalhando com uma concepção multidimensional das desigualdades.

Partindo da estrutura de relações entre amigos e/ou cônjuges, a abordagem proposta por Chan e Goldthorpe (2004), e baseada na Camsis, procura justamente construir uma escala de distâncias sociais, entre categorias ocupacionais, que possa ser interpretada como uma hierarquia de status. Do ponto de vista metodológico, a similaridade é muito grande com aquela dos pesquisadores de Cambridge. Do ponto de vista teórico, entretanto, Chan e Goldthorpe (2007) não apenas mantêm como procuram enfatizar, e comprovar - através de testes empíricos -, a interpretação daquela escala como indicadora apenas da dimensão social (em oposição à dimensão material) da estratificaçáo.

Tomando o trabalho destes últimos autores como referência, passamos a apresentar os resultados da aplicação da mesma metodologia para o Brasil, utilizando dados da PNAD 2013.

\section{Uma escala de status para o Brasil}

A construção da escala de status proposta por Chan e Goldthorpe (2004) envolve quatro passos. $\mathrm{O}$ primeiro deles remete à necessidade de agregar as informaçóes ocupacionais em categorias maiores. Essa etapa varia de país para país, já que em 
diferentes países há diferentes classificaçóes ocupacionais. ${ }^{15}$ Além disso, os critérios para essa agregação também são flexíveis, pois dependem de uma série de fatores, como o tamanho da amostra e a distribuição dos casos através das ocupações. De todo modo, o objetivo geral é conseguir definir um sistema de agregaçáo que gere categorias as mais internamente homogêneas possível, mas que tenham também uma quantidade de casos suficientemente grande para permitir a análise.

O principal pressuposto dessa metodologia é o de que as informações ocupacionais são relevantes do ponto de vista das hierarquias sociais (Chan e Goldthorpe, 2004). Seja pela natureza das tarefas que cada ocupação impóe ao indivíduo, seja pelos atributos (como educação ou rendimentos, por exemplo) normalmente encontrados entre aqueles que desempenham tais tarefas, acreditamos ser difícil rejeitar tal pressuposto. Além disso, a maior parte da literatura contemporânea sobre estratificação social, em suas mais diversas abordagens, parece concordar com a centralidade das ocupaçóes na sociedade moderna (Goldthorpe, 2000; Wright, 1989; Blau e Duncan, 1967; Weeden e Grusky, 2004).

Dado o elevado número de casos da PNAD ao menos quando comparado com amostras de locais como o Reino Unido -, conseguimos agregar as ocupações em 36 categorias de tamanho suficientemente grande para permitir a nossa análise. ${ }^{16}$ Nosso critério mais geral foi o de respeitar a CBO (Classificação Brasileira de Ocupaçôes), agregando as ocupações para sua versão de dois dígitos. Posteriormente, dado o tamanho elevado ou insuficiente de algumas categorias, e respeitando o critério da natureza das ocupaçóes, fizemos alguns ajustes. ${ }^{17}$

$\mathrm{Na}$ Tabela 1, temos a descrição das categorias ocupacionais com as quais trabalhamos e a composição das mesmas - segundo os códigos da $\mathrm{CBO}$-, assim como sua participação percentual no total da população ocupada.

Tabela 1

Descrição das categorias ocupacionais

\begin{tabular}{|c|c|c|c|}
\hline Número & Títulos & Composição (CBO) & $\%$ \\
\hline 1 & Militares das forças armadas & $100-300$ & 0,36 \\
\hline 2 & Policiais e bombeiros & $401-513$ & 0,54 \\
\hline 3 & Membros superiores e dirigentes do poder público & $1111-1140$ & 0,29 \\
\hline 4 & Dirigentes de empresas e organizaçóes & $1210-1230$ & 1,30 \\
\hline 5 & Gerentes de produção e operação & 1310 & 2,21 \\
\hline 6 & Gerentes de áreas de apoio & 1320 & 1,30 \\
\hline 7 & Profissionais das ciências exatas, física, engenharia e afins & $2011-2153$ & 1,03 \\
\hline 8 & Profissionais das ciências biológicas, da saúde e afins & $2211-2237$ & 1,34 \\
\hline 9 & Profissionais do ensino & $2311-2340$ & 3,57 \\
\hline 10 & Profissionais das ciências jurídicas & $2410-2423$ & 0,73 \\
\hline 11 & Profissionais das ciências sociais e humanas & $2511-2531$ & 1,47 \\
\hline 12 & Comunicadores, artistas e religiosos & $2611-2631$ & 1,01 \\
\hline 13 & Técnicos de nível médio das ciências físicas, químicas, engenharia e afins & $3001-3192 ; 3911-3912$ & 1,73 \\
\hline 14 & Técnicos de nível médio das ciências biológicas, da saúde e afins & $3201-3281$ & 1,19 \\
\hline 15 & Professores leigos e de nível médio & $3311-3341$ & 0,88 \\
\hline 16 & Técnicos de nível médio em serviços de transportes & $3411-3426$ & 0,08 \\
\hline 17 & Técnicos de nível médio nas ciências administrativas & $3511-3548$ & 2,44 \\
\hline 18 & Técnicos de nível médio nos serviços culturais, da comunicação e desportos & $3711-3773$ & 0,48 \\
\hline
\end{tabular}




\begin{tabular}{|c|c|c|c|}
\hline 19 & Escritutários & $4101-4152$ & 6,83 \\
\hline 20 & Trabalhadores de atendimento ao público & $4201-4241$ & 3,28 \\
\hline 21 & Trabalhadores nos serviços domésticos em geral & 5121 & 5,44 \\
\hline 22 & $\begin{array}{l}\text { Trabalhadores dos serviços de transporte, turismo, alimentação, hotelaria } \\
\text { e afins }\end{array}$ & $\begin{array}{l}5101 ; 5111-5114 \\
5131-5142\end{array}$ & 6,88 \\
\hline 23 & Trabalhadores dos serviços de saúde e cuidados pessoais & $5102 ; 5151-5169$ & 3,37 \\
\hline 24 & Trabalhadores dos serviços de proteção e segurança & $5103 ; 5171-5174$ & 2,21 \\
\hline 25 & Catadores, entregadores e outros trabalhadores dos serviços & $5191-5199$ & 1,66 \\
\hline 26 & Vendedores e prestadores de serviços do comércio & $5201-5231$ & 7,76 \\
\hline 27 & Vendedores a domicílios, em quiosques/barracas e ambulantes & $5241-5243$ & 1,75 \\
\hline 28 & Produtores rurais & 6110-6139 & 3,70 \\
\hline 29 & Trabalhadores rurais, pescadores, caçadores e extrativistas & $6201-6430$ & 10,60 \\
\hline 30 & Trabalhadores da indústria extrativa e da construção civil & $7101-7170$ & 8,57 \\
\hline 31 & Trabalhadores da indústria de transformaçáo de metais e de compósitos & $7201-7257$ & 2,10 \\
\hline 32 & $\begin{array}{l}\text { Trabalhadores da fabricação/instalação eletroeletrônica, de aparelhos de } \\
\text { precisão e afins }\end{array}$ & 7301-7524 & 0,41 \\
\hline 33 & Trabalhadores das indústrias têxteis, da madeira, mobiliário etc & $7601-7772$ & 3,40 \\
\hline 34 & Trabalhadores de funçôes transversais na indústria & $7801-7842$ & 5,64 \\
\hline 35 & Trabalhadores das indústrias de processos contínuos e outras indústrias & $8101-8711$ & 1,97 \\
\hline 36 & Trabalhadores do setor de manutenção, conservação e reparação & $9101-9992$ & 2,48 \\
\hline
\end{tabular}

Fonte: PNAD, 2013 (IBGE), elaboração própria.

O segundo passo, então, após terem sido criadas as categorias ocupacionais, é cruzar as categorias dos chefes de domicílio com as de seu cônjuge. Nesse ponto, conforme já comentamos anteriormente, há variações entre países que utilizam informaçóes de amizade e países que utilizam informaçóes de matrimônio. Chan e Goldthorpe (2004), por exemplo, utilizaram as informaçóes ocupacionais dos entrevistados e de seu amigo mais próximo, já que contavam com um survey dessa natureza. No caso do Brasil, fizemos uso das informações dos cônjuges, presentes tanto nas PNADs quanto nos censos (IBGE). ${ }^{18}$

No terceiro passo, depois de feito esse cruzamento, são calculados os percentuais de linha (que representam os chefes de domicílio), e entâo extraídos, para cada par de linhas, o índice de dissimilaridade. ${ }^{19}$

Finalmente, a matriz (ou metade dela) composta pelas dissimilaridades entre cada um dos pares de categorias ocupacionais é utilizada como input para uma análise de multidimensional scaling (MDSCAL). ${ }^{20} \mathrm{O}$ objetivo aqui é representar nossas 36 categorias ocupacionais como pontos num espaço multidimensional, de modo que a MDSCAL busca, através de método iterativo, a soluçáo cujas distâncias nesse espaço mais se aproximem das dissimilaridades observadas entre as categorias. ${ }^{21}$ Como resultado, somos capazes de reduzir os inúmeros índices de dissimilaridade em algumas poucas dimensões, facilitando a interpretação e identificação de algum padrão de distâncias sociais.

O primeiro procedimento na MDSCAL é definir o número de dimensóes - ou eixos - com os quais iremos trabalhar. Para tanto, toma-se como critério os valores de stress, que buscam fornecer uma medida do grau em que as distâncias computadas se aproximam das (dis)similaridades observadas. Basicamente, quando maior o valor do stress, menor o poder de explicação da análise. No Gráfico 1, temos os valores de stress segundo o número de eixos extraídos. 


\section{Gráfico 1}

Valores de Stress da Multidimensional Scaling

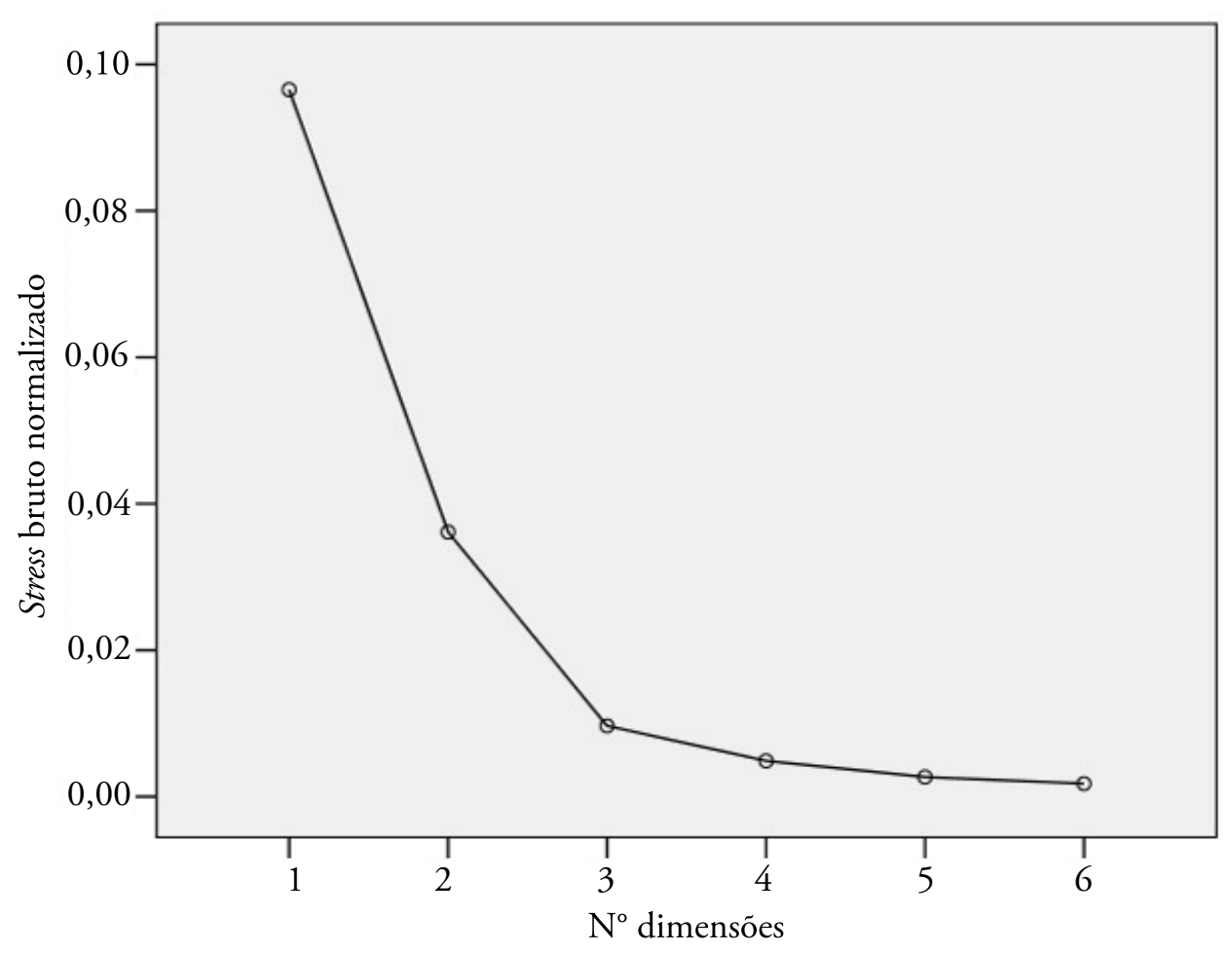

Fonte: PNAD, 2013 (IBGE), elaboração própria.

$\mathrm{O}$ valor de stress varia entre 0 e 1 , assumindo valor 0 quando a soluçáo apresentada pela MDSCAL representa perfeitamente as (dis)similaridades originais. Como podemos esperar, o stress decresce à medida que acrescentamos dimensóes à análise. Nesse gráfico, vemos que há uma queda bastante acentuada quando passamos da solução com apenas uma dimensão para a solução com duas dimensóes e, então, para a solução com três dimensóes. A partir de três, entretanto, dimensóes adicionais contribuem muito pouco para a reduçáo de stress. Por essa razão, assim como Chan e Goldthorpe (2004), trabalharemos com a solução de três dimensóes, cujo stress era de 0,096, indicando um ajuste bastante adequado aos dados.

O próximo passo, então, é interpretar essas três dimensôes extraídas a partir da MDSCAL. Trata-se de um ponto fundamental para a nossa análise, já que buscamos averiguar se alguma dessas dimensóes poderia ser identificada como uma hierarquia de status social. Chan e Goldthorpe (2004), assim como Laumann (1973), Laumann e Guttman (1966), Stewart, Prandy e Blackburn (1980), identificaram a primeira dimensão como aquela que representaria status. No entanto, enquanto Chan e Goldthorpe (2004) procuram atribuir algum significado às outras duas dimensões, associando-as ao percentual de mão de obra feminina (segunda dimensão) e, de modo menos preciso, à segregaçáo do contexto ocupacional (terceira dimensão), os demais estudos não foram capazes de interpretá-las. ${ }^{22}$

A fim de analisar o caso brasileiro, construímos o Gráfico 2 com a projeção das categorias ocupacionais nos planos formados pelas três dimensões, extraídas a partir da solução oferecida pela MDSCAL. 
Gráficos 2a e 2b

Projeçóes Planas das Soluçóes da MDSCAL
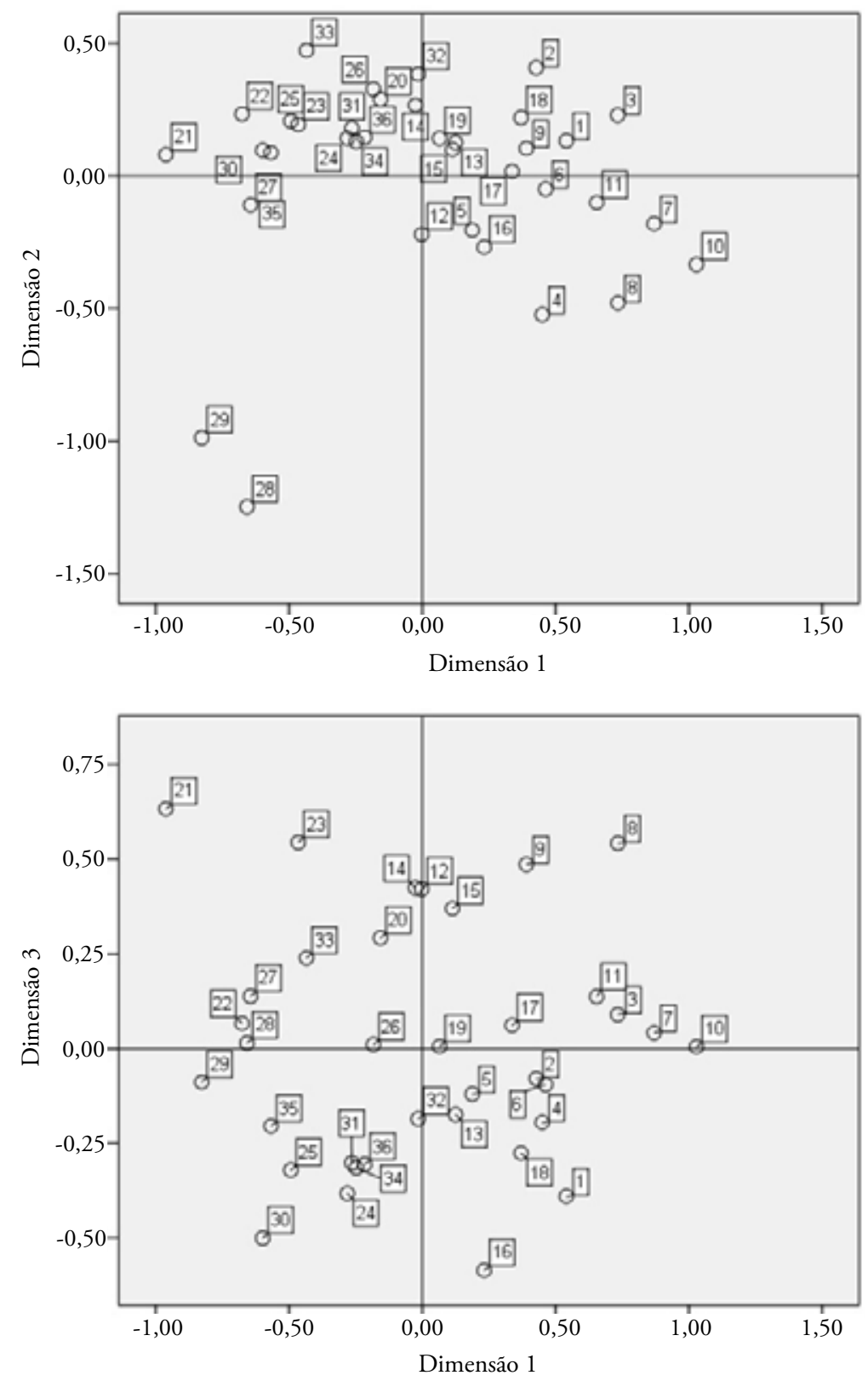

Fonte: PNAD, 2013 (IBGE), elaboração própria.

O Gráfico 2a forma um plano a partir da primeira (eixo horizontal) e segunda (eixo vertical) dimensôes. Já Gráfico $2 \mathrm{~b}$ cruza a primeira (eixo horizontal) com a terceira (eixo vertical) dimensão. Em ambos os gráficos, os pontos acompanham marcadores indicando as categorias ocupacionais que representam, conforme apresentado na Tabela 1. Basicamente, pontos mais próximos indicam categorias ocupacionais entre as quais encontramos relações de matrimônio de modo mais típico, e 
maiores distâncias indicam menores chances desse tipo de relação entre as respectivas categorias.

Assim como ocorre nos estudos aplicados a outros países, acreditamos que também neste caso a primeira dimensão possa ser interpretada como uma hierarquia de status social. Vemos que a categoria com score mais alto nesse eixo, aquela que se encontra mais à direita nos Gráficos $2 \mathrm{a}$ e $2 \mathrm{~b}$, é a dos Profissionais das Ciências Jurídicas (10), seguida dos Profissionais das Ciências Exatas, Física, Engenharia e afins (7), dos Profissionais das Ciências Biológicas, da Saúde e afins (8), dos Membros Superiores e Dirigentes do Poder Público (3), e dos Profissionais das Ciências Sociais e Humanas (11). No extremo oposto desse eixo, mais à esquerda, e com os scores mais baixos, nós identificamos os Trabalhadores nos Serviços Domésticos (21), seguidos dos Trabalhadores Rurais (29) e dos Trabalhadores dos Serviços de Transporte, Turismo, Alimentação, Hotelaria e afins (22). Na próxima seçáo, examinaremos essa primeira dimensão de modo mais detalhado.

Quanto aos outros eixos, vemos que, no caso da segunda dimensão, fica bastante evidente a maneira como as categorias ocupacionais rurais são discriminadas, se destacando das demais. No Gráfico 2a, as categorias 28 (Produtores Rurais) e 29 (Trabalhadores Rurais, Pescadores e Extrativistas) se opõem a todas as demais, localizando-se de modo claro, e isoladas, na parte inferior. Temos, portanto, uma dimensão que procura dar conta das peculiaridades dessas duas categorias, que se concentram em atividades primárias, no meio rural. Além disso, esse segundo eixo apresenta uma relação acentuada com a idade dos indivíduos. A correlaçáo de Pearson entre essa dimensão e a média de idade dos indivíduos em cada uma das categorias ocupacionais é de $-0,637^{23}$; quanto maior a média de idade dos indivíduos, menor tende a ser o score nesse eixo.

No caso do Brasil, portanto, a segunda dimensão discrimina as ocupaçóes rurais e, além disso, ordena as categorias de acordo com a média de idade.

O terceiro eixo extraído, por sua vez, está relacionado com a segregação de gênero presente nas categorias ocupacionais. A correlação de Pearson entre essa dimensão e o percentual de mulhe- res é bastante acentuada: $0,903 .{ }^{24} \mathrm{Ou}$ seja, quanto maior o score da categoria nesse eixo, maior tende a ser o percentual de mão de obra feminina. Por essa razão, no topo dessa dimensão, encontramos a categoria dos Trabalhadores nos Serviços Domésticos (21), composta por $92 \%$ de mulheres, seguida dos Trabalhadores dos Serviços de Saúde e Cuidados Pessoais (23), com $88 \%$ de máo de obra feminina. No extremo oposto da escala, com percentuais muito baixos de participação feminina, temos categorias como Militares das Forças Armadas (1), Trabalhadores do Serviço de Proteção e Segurança (24), Trabalhadores da Indústria Extrativa e da Construção Civil (30) e Técnicos de Nível Médio em Serviços de Transportes (16).

Todas as três dimensóes resultantes da MDSCAL podem ser interpretadas de modo significativo, o que corrobora nossa decisão de trabalhar com esse número de eixos. Ao contrário do que acontece no caso inglês, tratado por Chan e Goldthorpe (2004), é a nossa terceira dimensão, e não a segunda, que discrimina as categorias pelo percentual de mulheres. Além disso, o segundo eixo extraído possui uma interpretação bastante clara, destacando as ocupaçóes rurais e, além disso, ordenando as categorias segundo a média de idade dos indivíduos.

Como o segundo e terceiro eixos se mostraram relacionados com segregação de gênero, contexto urbano ou rural e idade, podemos esperar que a primeira dimensão se encontre livre desses fatores, que poderiam confundir nossa interpretaçáo da mesma como uma hierarquia de status. A fim de melhor examinar essa hierarquia, na próxima seção analisaremos o primeiro eixo extraído.

\section{Hierarquia de status}

É interessante observar que a primeira dimensão extraída de nossa análise, da qual examinaremos sua validade como uma hierarquia de status, tenha os Profissionais das Ciências Jurídicas no topo, e os Empregados Domésticos ocupando a última posição. A Tabela 2 traz as categorias ordenadas segundo seu score nessa escala, facilitando a visualização dessa hierarquia. 
Tabela 2

Categorias Ocupacionais, por sua Posiçáo na Hierarquia de Status, Scores e Participaçáo na Populaçáo Ocupada (\% acumulado) (Brasil, 2013)

\begin{tabular}{|c|c|c|c|}
\hline Posiçáo & Categorias & Scores & $\%$ acum. \\
\hline 1 & Profissionais das ciências jurídicas & 1,03 & 0,7 \\
\hline 2 & Profissionais das ciências exatas, física, engenharia e afins & 0,87 & 1,8 \\
\hline 3 & Membros superiores e dirigentes do poder público & 0,73 & 2,0 \\
\hline 4 & Profissionais das ciências biológicas, da saúde e afins & 0,73 & 3,4 \\
\hline 5 & Profissionais das ciências sociais e humanas & 0,65 & 4,8 \\
\hline 6 & Militares das forças armadas & 0,54 & 5,2 \\
\hline 7 & Gerentes de áreas de apoio & 0,46 & 6,5 \\
\hline 8 & Dirigentes de empresas e organizaçóes & 0,45 & 7,8 \\
\hline 9 & Policiais e bombeiros & 0,43 & 8,3 \\
\hline 10 & Profissionais do ensino & 0,39 & 11,9 \\
\hline 11 & Técnicos de nível médio nos serviços culturais, da comunicação e desportos & 0,37 & 12,4 \\
\hline 12 & Técnicos de nível médio nas ciências administrativas & 0,34 & 14,8 \\
\hline 13 & Técnicos de nível médio em serviços de transportes & 0,23 & 14,9 \\
\hline 14 & Gerentes de produção e operação & 0,19 & 17,1 \\
\hline 15 & Técnicos de nível médio das ciências físicas, químicas, engenharia e afins & 0,13 & 18,9 \\
\hline 16 & Professores leigos e de nível médio & 0,11 & 19,7 \\
\hline 17 & Escritutários & 0,06 & 26,6 \\
\hline 18 & Comunicadores, artistas e religiosos & 0,00 & 27,6 \\
\hline 19 & Trabalhadores da fabricaçáo/instalaçáo eletroeletrônica, de aparelhos de precisão e afins & $-0,02$ & 28,0 \\
\hline 20 & Técnicos de nível médio das ciências biológicas, da saúde e afins & $-0,03$ & 29,2 \\
\hline 21 & Trabalhadores de atendimento ao público & $-0,16$ & 32,5 \\
\hline 22 & Vendedores e prestadores de serviços do comércio & $-0,18$ & 40,2 \\
\hline 23 & Trabalhadores do setor de manutenção, conservação e reparação & $-0,22$ & 42,7 \\
\hline 24 & Trabalhadores de funções transversais na indústria & $-0,25$ & 48,3 \\
\hline 25 & Trabalhadores da indústria de transformação de metais e de compósitos & $-0,26$ & 50,4 \\
\hline 26 & Trabalhadores dos serviços de proteção e segurança & $-0,28$ & 52,7 \\
\hline 27 & Trabalhadores das indústrias têxteis, da madeira, mobiliário etc & $-0,43$ & 56,1 \\
\hline 28 & Trabalhadores dos serviços de saúde e cuidados pessoais & $-0,47$ & 59,4 \\
\hline 29 & Catadores, entregadores e outros trabalhadores dos serviços & $-0,49$ & 61,1 \\
\hline 30 & Trabalhadores das indústrias de processos contínuos e outras indústrias & $-0,57$ & 63,1 \\
\hline 31 & Trabalhadores da indústria extrativa e da construçáo civil & $-0,6$ & 71,6 \\
\hline 32 & Vendedores a domicílios, em quiosques/barracas e ambulantes & $-0,64$ & 73,4 \\
\hline 33 & Produtores rurais & $-0,66$ & 77,1 \\
\hline 34 & Trabalhadores dos serviços de transporte, turismo, alimentação, hotelaria e afins & $-0,68$ & 84,0 \\
\hline 35 & Trabalhadores rurais, pescadores, caçadores e extrativistas & $-0,83$ & 94,6 \\
\hline 36 & Trabalhadores nos serviços domésticos em geral & $-0,96$ & 100,0 \\
\hline
\end{tabular}

Fonte: PNAD, 2013 (IBGE), elaboração própria. 
Muitas das características da hierarquia descrita na Tabela 2 são semelhantes às escalas desenvolvidas em países como Inglaterra, Chile e Estados Unidos. O primeiro ponto, bastante importante, diz respeito à parte superior da tabela, acima da linha tracejada, que separada aproximadamente as categorias com score mais elevado que somavam $20 \%$ da mão de obra ocupada no país em 2013. Também no caso brasileiro, percebemos a tendência de os profissionais ocuparem as posiçóes de $s$ tatus superior, em geral acima dos Gerentes e Dirigentes de empresas. É na parte de cima da tabela que encontramos, além dos Profissionais das Ciências Jurídicas, os Profissionais das Ciências Exatas, Física, Engenharia e afins, os Profissionais das Ciências Biológicas, da Saúde e afins e os Profissionais das Ciências Sociais e Humanas.

Essa supremacia dos profissionais em relação aos proprietários, gerentes e administradores pode ser considerada um primeiro indicador de que nossa escala exprime uma hierarquia de status, dado que parte da literatura sobre o tema destaca a maior importância do capital cultural, em relação ao capital econômico, sobre o prestígio dos grupos sociais (Bourdieu, 2008; Chan e Goldthorpe, 2004; Weber, 1953).

Entre os Gerentes e Dirigentes, por sua vez, destacam-se os Membros Superiores e Dirigentes do Poder Público, ocupando a terceira posição, em meio aos profissionais. Gerentes de Área de Apoio e Dirigentes de Empresas e Organizaçóes ocupam, respectivamente, a sétima e oitava posiçóes. Já a categoria dos Gerentes de Produção e Operação, que engloba muitos pequenos proprietários, ficou apenas na décima quarta colocação. De todo modo, a tendência é de encontrarmos, no topo dessa hierarquia, os profissionais, membros do poder público, dirigentes e gerentes.

Além desses, é muito interessante a presença, ainda no topo da Tabela 2, dos Militares das Forças Armadas, na sexta posição, e dos Policiais e Bombeiros, na nona posição, em meio, portanto, às categorias citadas no parágrafo anterior. Sabemos que não se trata de ocupaçóes com grande poder econômico, ou chances no mercado próximas/semelhantes à de profissionais e/ou dirigentes. Caso nossa escala representasse poder econômico, dificilmente essas categorias estariam ocupando seu topo.
Sabemos também que categorias militares sempre tiveram a tendência de ocupar, ao longo da história, posições de status social relativamente elevado. ${ }^{25}$ Nesse sentido, a posição dessas categorias, próximas ao topo de nossa escala, reforça sua interpretação como uma hierarquia de status.

Já mais próximos da base da tabela, localizamos principalmente as categorias de trabalhadores manuais, o que também é bastante semelhante ao que foi encontrado em outros países (Chan, 2010). Abaixo da linha tracejada, que separa as categorias inferiores que agregavam aproximadamente $40 \%$ da população ocupada no Brasil em 2013, encontramos alguns grupos de trabalhadores da indústria (construção civil, extrativa etc.), dos serviços (cuidados pessoais, catadores, entregadores e domésti$\cos$ ), do setor rural e, também, vendedores em domicílio, em quiosques/barracas e ambulantes.

Temos aqui, no entanto, uma diferença importante em relaçáo a muitos dos exercícios de construção dessa escala em outros países, especialmente na Europa e nos Estados Unidos. Como fruto de nosso processo de modernização, há no Brasil - assim como em muitos países latino-americanos - um enorme contingente de trabalhadores que vive nas franjas do sistema econômico, em situaçóes muitas vezes precárias e instáveis (Fernandes, 2009). Verificamos na parte inferior da Tabela 2, ocupando entấo as últimas posiçóes da escala, categorias como a dos Trabalhadores Domésticos, Vendedores em Domicílio, Ambulantes, Trabalhadores da Construção Civil, Entregadores, Catadores etc. Trata-se, portanto, de uma importante particularidade da escala construída para o Brasil: a presença de significativo número de categorias com status inferior ao dos trabalhadores da indústria (especialmente a moderna) e do comércio, formada principalmente por trabalhadores dos serviços urbanos não especializados. Dentre os países para os quais essa escala já foi construída, apenas o Chile - outro país sul-americano apresenta resultados similares a esse respeito.

Nessa parte inferior também é interessante notar que as categorias do setor rural não ocupam as últimas posiçóes - que seria o esperado caso se tratasse apenas de uma escala indicadora de distâncias sociais. ${ }^{26}$ Isso acontece, é claro, por conta da extração de outras dimensóes, que livraram essa escala dos efeitos de fatores 
externos, como a divisão rural/urbano, reforçando sua interpretação como uma hierarquia de status. Como já mencionamos, a categoria que ocupa a última posição não é a dos Trabalhadores Rurais, mas sim a dos Trabalhadores nos Serviços Domésticos.

Já na seção intermediária dessa escala, encontramos, principalmente, Técnicos de Nível Médio, Professores de Nível Médio, Escriturários, Trabalhadores de Atendimento ao Público e Vendedores e Prestadores de Serviço do Comércio, entre outros. $\mathrm{Na}$ camada intermediária da hierarquia, especialmente entre as posiçôes de número 11 e 22 , concentram-se, portanto, técnicos (nível médio), trabalhadores não manuais de rotina e/ou do comércio. A partir da posição de número 23 , até a última categoria, concentram-se os trabalhadores da indústria, os rurais e de serviços - com algumas exceções.

Assim como acontece para outros países, há clara relação dessa hierarquia com o caráter manual ou não das ocupaçóes, de maneira que as categorias cujas tarefas sejam de cunho manual tendem a apresentar scores mais baixos. Como nas sociedades modernas, devido à complexidade da divisão do trabalho, ao crescimento do setor de serviços etc., não podemos estabelecer uma clara divisão entre setor manual e não manual, categorias intermediárias - como técnicos e empregados/trabalhadores no serviço e comércio - tendem a ocupar as posições do meio daquela hierarquia.

É possível, então, observarmos certa lógica na escala apresentada, descrita anteriormente, que, de maneira geral, se assemelha ao que ocorre em outros países, e corrobora nossa interpretação como uma hierarquia de status.

\section{Hierarquia de status, escolaridade e rendimentos}

Será que essa hierarquia estaria relacionada com fatores como rendimentos e escolaridade? Se sim, qual forma assumiria essa relação, e a qual das duas variáveis estaria relacionada de maneira mais clara? A fim de fornecermos respostas a essas questôes, construímos gráficos de dispersão cruzando estas informações (Gráficos 3a e 3b).

\section{Gráficos 3a e 3b}

Gráficos de Dispersáo para o Cruzamento entre Scores de Status, Escolaridade e Rendimentos (Brasil, 2013)

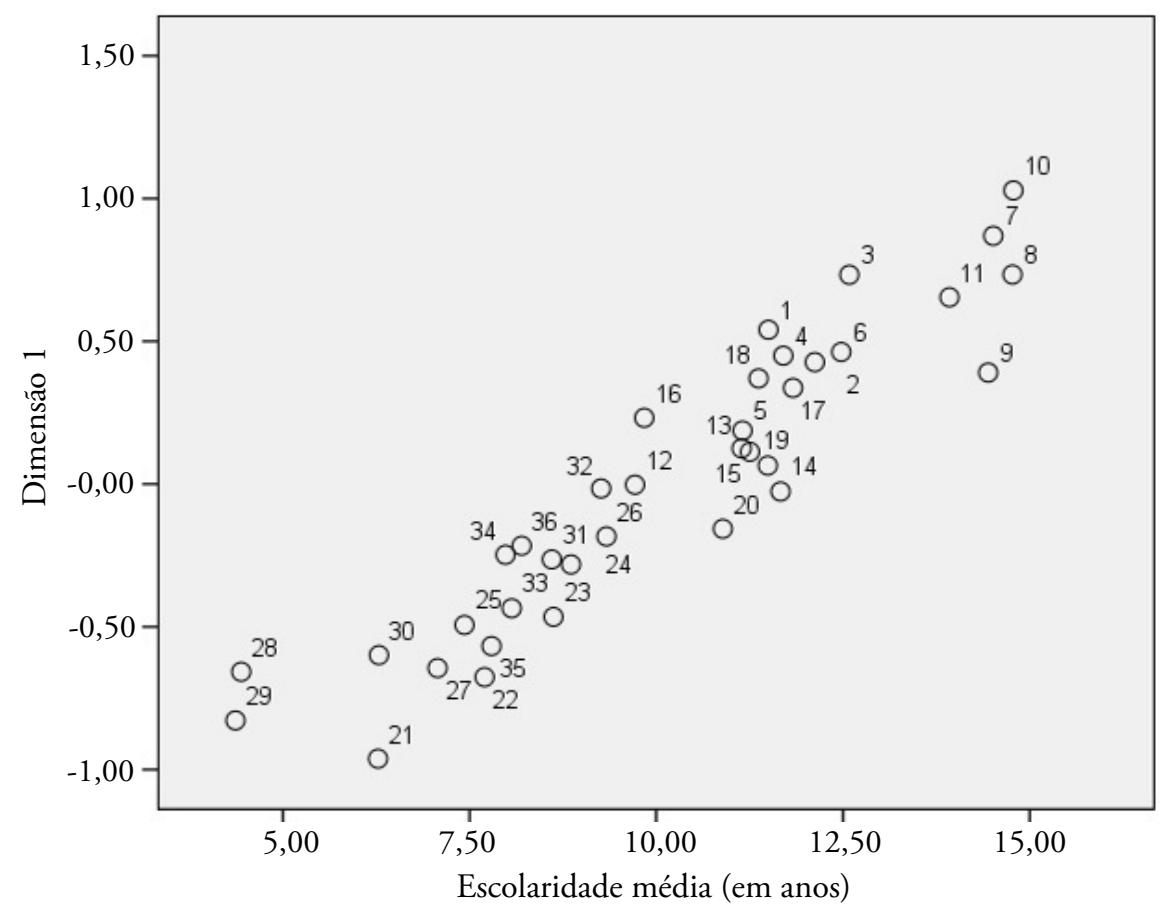

Fonte: PNAD, 2013 (IBGE), elaboração própria. 


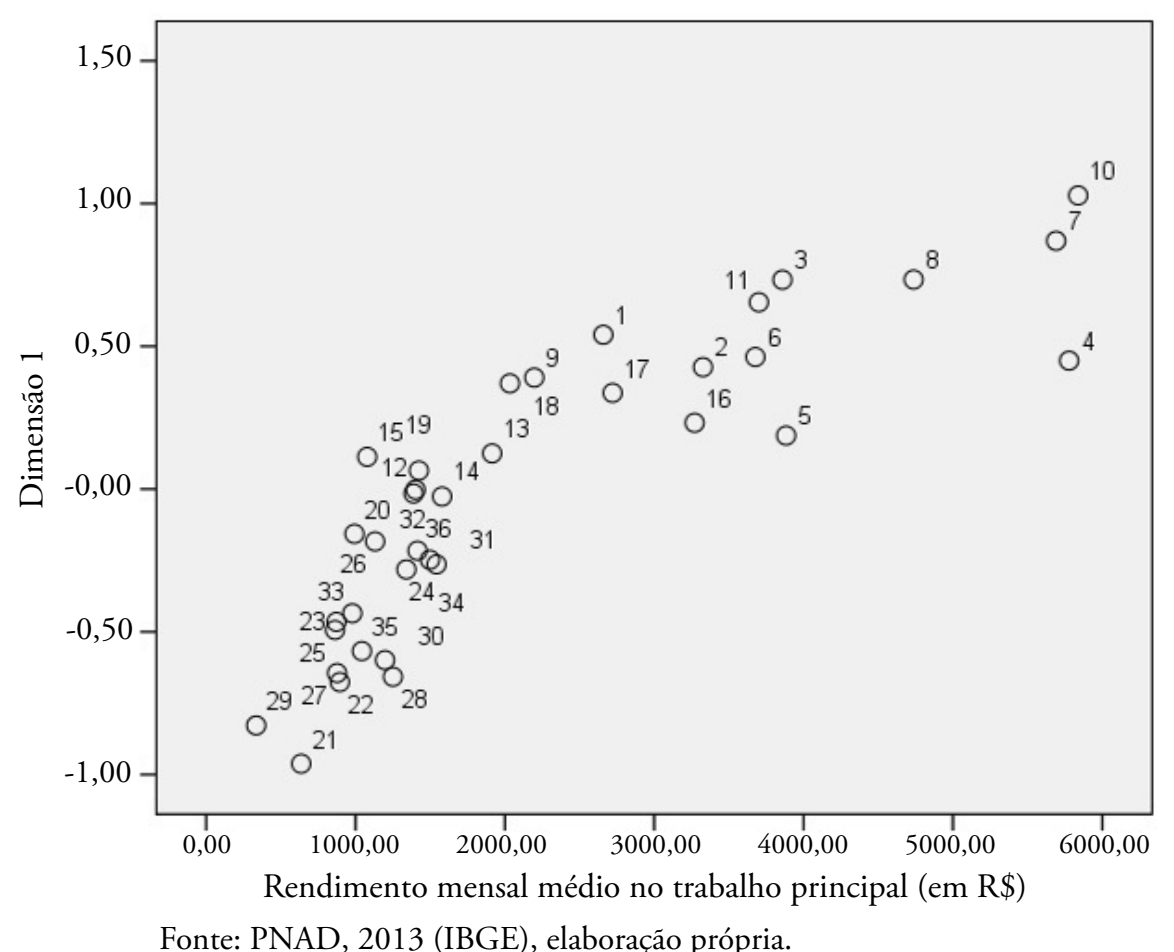

Fonte: PNAD, 2013 (IBGE), elaboração própria.

O Gráfico 3a traz o cruzamento entre a média de anos de escolaridade dos indivíduos que compóem as 36 categorias ocupacionais, e os scores das mesmas na escala de status. Como se pode ver, temos aqui uma clara correlação linear, cujo coeficiente de Pearson é de $0,935,{ }^{27}$ indicando uma relação bastante acentuada entre status e escolaridade. Destarte, quanto maior a média de escolaridade, maior tende a ser o score da categoria.

No Gráfico 3b, por sua vez, temos a relação entre a média do rendimento mensal do trabalho principal (em reais), para as 36 categorias ocupacionais, e seus scores na escala de status. Diferentemente do que acontece para o caso da escolaridade, conforme pode ser notado, a relaçáo entre renda e status não se dá de forma linear, de maneira que enquanto pequenas variaçóes em níveis baixos de rendimentos parecem se relacionar com melhoras acentuadas de status, nas camadas de rendimento mais alto - a partir, mais ou menos, de 2 mil reais -, aquela relação assume uma forma menos acentuada. Assim, parece ser correto afirmar que, ao menos no Brasil, um mínimo de renda é bastante impor- tante para afirmar seu status, mas que, a partir de certo ponto, os rendimentos se tornam bem menos relevantes nesse sentido.

A fim de obter o coeficiente de correlação de Pearson, então, calculamos o logaritmo natural da renda, e o cruzamos, novamente, com os scores de status. Tendo transformado a relação entre renda e scores em uma relaçáo linear, o coeficiente de Pearson ficou em $0,909,{ }^{28}$ indicando uma relação também acentuada e positiva, porém com intensidade um pouco menor - mas ainda muito alta - do que no caso de escolaridade.

Esses resultados também coincidem, em certa medida, com aqueles alcançados em outros países, que indicam correlaçáo alta - mas com intensidades variáveis - entre a escala de status e medidas de rendimento e escolaridade, sendo a relação um pouco mais forte para esta segunda variável. Podemos afirmar que, do ponto de vista teórico, esse também seria um resultado esperado. Apesar da distinçáo conceitual, espera-se que o status social esteja relacionado com indicadores como renda e escolaridade. Além disso, espera-se também que essa 
relação seja mais forte com a escolaridade, dado que tradicionalmente as credenciais educacionais e capital cultural tendem a conferir bastante prestígio a seus portadores, de modo mais evidente que o simples acúmulo de riquezas (Bourdieu, 2008).

No entanto, para afirmar que o efeito da escolaridade sobre o status é superior ao efeito da renda, os resultados expostos anteriormente não são sufi- cientes, dado que ambas as variáveis estão também fortemente relacionadas. Para que possamos obter dados mais substantivos a esse respeito, trabalhamos com um modelo de regressão linear, inserindo os scores indicadores de status como variável dependente, e as médias de escolaridade e renda como variáveis independentes. Os resultados encontram-se na Tabela 3.

Tabela 3

Regressáo Linear (OLS) da Escala de Status por Escolaridade e Rendimentos (log) (Brasil, 2013)

\begin{tabular}{lccccc}
\hline $\begin{array}{c}\text { Variáveis } \\
\text { independentes }\end{array}$ & Beta & Erro pd. & Std. Beta & t & sig. \\
\hline Constante & $-3,530$ & 0,321 & - & $-10,997$ & 0,000 \\
\hline Escolaridade & 0,107 & 0,014 & 0,577 & 7,605 & 0,000 \\
\hline Rendimentos $(\log )$ & 0,328 & 0,057 & 0,437 & 5,760 & 0,000 \\
\hline
\end{tabular}

Fonte: PNAD, 2013 (IBGE), elaboração própria.

Em primeiro lugar, devemos informar que o modelo rodado apresenta coeficiente de determinação $\left(\mathrm{R}^{2}\right)$ no valor de 0,937 , indicando um excelente ajuste aos dados, de modo que as variaçóes na hierarquia de status podem ser quase completamente explicadas, no caso brasileiro, por escolaridade e renda. $\mathrm{O}$ mesmo não ocorreu em outros países, nos quais apesar de um ótimo poder de explicação, o coeficiente de determinaçấo $\left(\mathrm{R}^{2}\right)$ não chegava a valores tão altos. Voltaremos a esse ponto mais adiante.

Vemos, na última coluna, mais à direita, que tanto escolaridade quanto rendimentos apresentam efeitos significativos ${ }^{29}$ sobre os scores, mesmo quando inseridas concomitantemente no modelo. A fim de compararmos os efeitos de uma e de outra, é preferível olhar para a quarta coluna (std. beta), onde se têm os coeficientes padronizados. Podemos notar, entáo, que o efeito padronizado da escolaridade $(0,577)$ é maior do que aquele dos rendimentos $(0,437)$.

Weber (1953) já afirmava que o status costuma estar mais associado à escolarização, consumo cultural e estilo de vida do que pura e simplesmente à riqueza material e econômica. Portanto, em confor- midade com o que seria esperado segundo o referencial teórico, e também de acordo com o que ocorre em outros países (Chan, 2010), a hierarquia de status construída para o Brasil se encontra mais relacionada com educação do que com rendimentos.

\section{Hierarquia de status e estratificação por classe}

Como vimos, Weber estabelece uma importante distinção conceitual entre classe e status - duas dimensões da estratificação -, mas sem perder de vista a possibilidade de as mesmas estarem estritamente relacionadas na realidade.

Enquanto o status se refere à distribuição de poder social, classe diz respeito ao poder econômico, às chances relativas de sucesso dos indivíduos no mercado. Neste artigo, nos preocupamos em construir uma escala que pudesse ser interpretada como indicadora de uma hierarquia de status. Para analisar a relação entre classe e status, portanto, deveremos utilizar, além da escala que criamos, alguma categorização indicadora de classes.

Felizmente, como já tivemos a oportunidade de afirmar, nos últimos anos uma série de estudos vêm 
desenvolvendo os chamados esquemas de classe, ou seja, classificaçóes que permitem aos pesquisadores dividir a população em diferentes categorias. Trabalharemos com aquele que internacionalmente é o mais conhecido dos esquemas de classe, o famoso EGP.

Desenvolvido por Erikson, Goldthorpe e Portocarero (1979, p. 37), o esquema de classes EGP é construído a partir das informaçóes ocupacionais, e seu objetivo é "diferenciar posiçóes dentro do mercado de trabalho e das unidades produtivas". $\mathrm{Na}$ construção desse esquema, o primeiro critério de distinção separa empregadores, autônomos e empregados. O segundo critério é aplicado somente aos empregados - que, em geral, conformam a maior parte da população ocupada nas sociedades modernas -, e separa as ocupaçóes levando em conta o tipo de relação de trabalho. Dessa maneira, o eixo de classificação vai dos trabalhadores manuais ou não manuais de baixo status, até os profissionais, administradores e gerentes.

O esquema EGP foi originalmente construído com onze categorias, mas aqui utilizaremos uma versão mais agregada, de 6 categorias (Bergman e Joye, 2001), que são as seguintes: Profissionais e Administradores, Trabalhadores Não Manuais de Rotina, Pequenos Proprietários, Trabalhadores Manuais Qualificados, Trabalhadores Manuais Não Qualificados e Trabalhadores Rurais. O Gráfico 4 traz a média e o desvio-padráo dos scores de status para os indivíduos agregados em cada uma das seis classes.

\section{Gráfico 4}

Média e Desvio-padráo dos Scores de Status para as Classes EGP (Brasil, 2013)

$\square$ Média $\square$ Desvio-Padrão

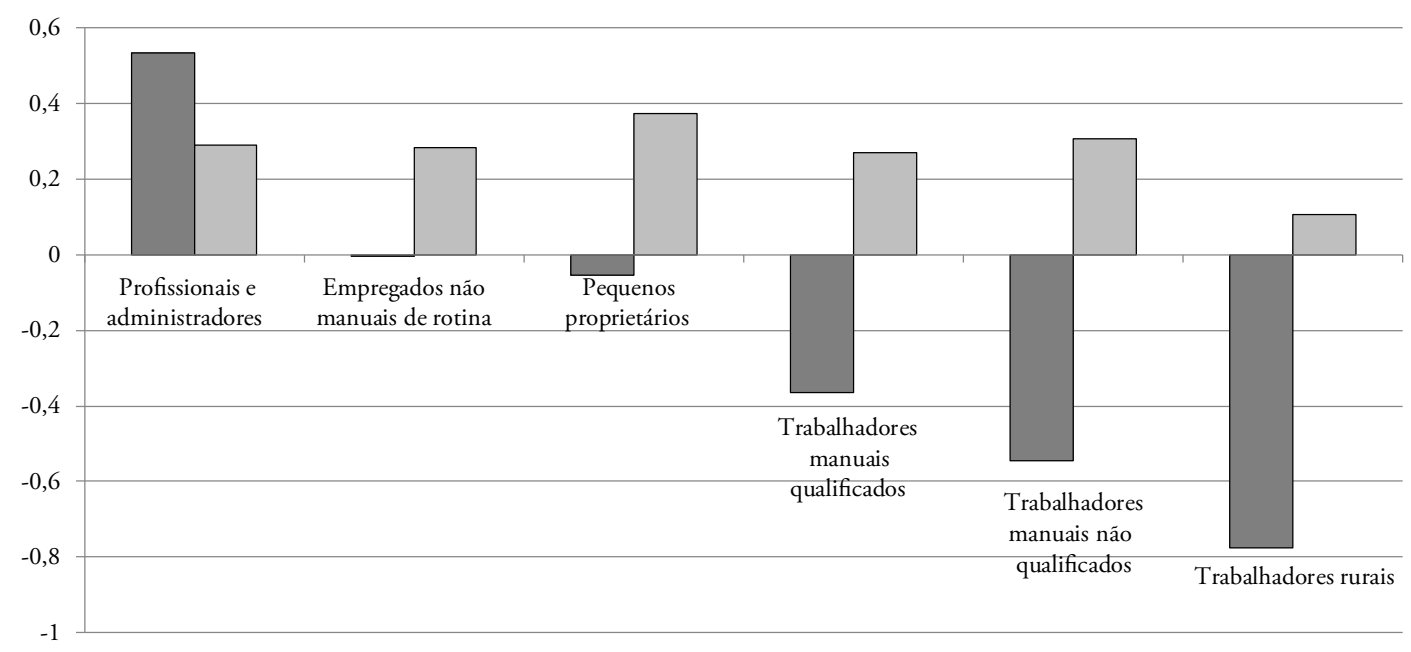

Fonte: PNAD, 2013 (IBGE), elaboração própria.

Vemos que, enquanto a dispersão dos scores de status, indicado pelo desvio-padrão, não parece variar muito entre as classes - com pequena tendência de alta entre os Pequenos Empregadores, e de baixa entre os Trabalhadores Rurais -, há evidente relação entre as classes e a média no score de status. Conforme seria esperado, os Profissionais e Admi- nistradores apresentam a média mais alta, no valor de 0,534 . Há acentuada queda, então, quando passamos para os Empregados Não Manuais de Rotina, cujo score médio é de -0,001. A média para os Pequenos Proprietários, entretanto, fica bem próxima àquela do grupo anterior, no valor de -0,054. A partir daí, constatamos uma queda acentuada e 
contínua das médias, chegando a $-0,366$ entre os Trabalhadores Manuais Qualificados, -0,546 para os Trabalhadores Manuais Não Qualificados e, finalmente, $-0,775$ para os Trabalhadores Rurais.

Notamos, então, em primeiro lugar, uma clara relação entre classe e status, conforme já era esperado e também já constatado para outros países (Chan e Wing, 2010). Em segundo lugar, é possível identificar três diferentes patamares de status entre as classes. Primeiramente, temos os Profissionais e Administradores num patamar bem mais elevado. Já os Empregados Não Manuais de Rotina e os Pequenos Empregadores ocupam posiçóes intermediárias e muito próximas. Finalmente, as classes de trabalhadores todas apresentam scores médios de status abaixo da média geral $(-0,282)$, de modo decrescente entre os Trabalhadores Manuais Qualificados e os Trabalhadores Rurais, passando pelos Trabalhadores Manuais Não Qualificados.

Portanto, apesar de analiticamente distintos, classe e status também se encontram bastante relacionados no caso do Brasil. Enquanto categorias como a de Profissionais e Administradores apresentam status elevado, os trabalhadores manuais, em especial aqueles pouco ou não qualificados, possuem status muito inferior à média nacional. É provável, então, que essas distintas dimensôes da estratificação se reforcem mutuamente.

\section{Conclusóes}

Os resultados apresentados neste artigo possibilitam responder às questóes colocadas inicialmente. Parece haver uma clara hierarquia de status do Brasil, na qual os profissionais, seguidos dos administradores e militares, ocupam o topo, e os trabalhadores manuais ocupam a base, sendo os trabalhadores domésticos a categoria com menor status. De modo geral, então, nessa hierarquia nós temos as ocupaçóes não manuais no topo e as ocupaçóes manuais na base, salvo exceçóes. Tais características foram, também, encontradas em outros países, e já podem ser consideradas uma tendência bem consolidada das escalas de status, apesar das peculiaridades de cada sociedade.

No caso do Brasil, assim como parece ocorrer em outros países latino-americanos, uma impor- tante particularidade é a presença de muitas categorias, com grande peso do setor de serviços urbanos, representando um enorme contingente de trabalhadores com status inferior (em alguns casos similar) ao das categorias ocupacionais da indústria e do comércio.

Nossa escala se mostrou bastante relacionada com fatores como rendimentos e, principalmente, educação, de modo que quanto maior a escolaridade e a renda, maior também tende a ser o status. Quando comparamos a trabalhos semelhantes realizados em outros países (Chan, 2010), no Brasil a relação da hierarquia de status com essas informaçóes é, aparentemente, mais acentuada. Finalmente, vimos que há uma clara relação entre classe e status no Brasil, já que Profissionais e Administradores tendem a apresentar status elevado, seguidos das camadas médias dos Pequenos Proprietários e Trabalhadores Não Manuais de Rotina e, enfim, chegando a níveis inferiores de status entre as classes trabalhadoras.

Tais resultados foram alcançados graças ao desenvolvimento de uma inovadora escala de status social para o Brasil. Tomando como referência o trabalho de Chan e Goldthorpe (2004, 2007), utilizamos as informaçóes cruzadas das categorias ocupacionais de chefes de domicílio, e seus cônjuges, como indicadores de distância social, a partir dos quais a escala foi criada - fazendo uso da técnica de optimal scalling.

Acreditamos que o desenvolvimento dessa escala pode proporcionar grande avanço nos estudos sobre status social. Conforme procuramos mostrar nas primeiras seçóes deste artigo, apesar da importante distinção analítica entre classe e status, elaborada por Max Weber, nos últimos anos apenas medidas de classe foram bem desenvolvidas (Goldthorpe, 2000; Wright, 1989). No caso do status, quando lembrado, foi tratado a partir de escalas que não o definiam corretamente, como aquelas baseadas em informaçóes do prestígio atribuído subjetivamente (Blau e Duncan, 1967) e/ou informaçóes de escolaridade e rendimento (Ganzeboom, De Graaf e Treiman, 1992). Ou então, em outra tradição de estudos, o status foi muitas vezes tomado apenas como a dimensão simbólica da estratificação por classes (Bourdieu, 2008). 
Mas, como vimos, a estratificação por status diz respeito à distribuição de honra e/ou prestígio social, atribuídos aos indivíduos em função de alguma característica de caráter coletivo (cor, gênero, origem social, nível de escolaridade, ocupação etc.), e que se expressa por meio de distâncias sociais estruturadas em relaçóes percebidas e, até certo ponto, aceitas, de superioridade, igualdade e inferioridade. Essa hierarquia de status poderia, então, ser identificada principalmente através das relações mais íntimas, como amizade e matrimônio, já que estas tenderiam a se restringir a grupos com status similar. Por outro lado, a desigualdade de status tenderia a ser representada pela distância social especialmente no que diz respeito às relaçóes de maior proximidade.

Com base nessa definição, Chan e Goldthorpe (2004, 2007) tomam a escala de distâncias sociais que já vinha sendo desenvolvida pelos pesquisadores de Cambridge (Prandy e Lambert, 2003) como indicadora da hierarquia de status social. Sem dúvi$\mathrm{da}$, a escala que desenvolveram, e que neste trabalho aplicamos para o Brasil, é uma escala de distâncias sociais. Sua interpretação como uma hierarquia de status, entretanto, ainda vem sendo validada por meio de estudos que procuram aplicá-la a outros países (Chan, 2010) e, também, testar sua relação fenômenos que esperaríamos que fossem muito relacionados com status - como, por exemplo, o consumo cultural (Chan e Goldthorpe, 2007). Até o momento, podemos afirmar, a maior parte das evidências sustentam a sua interpretação enquanto uma hierarquia de status social.

Sua aplicaçáo para o Brasil vem contribuir para essa agenda de pesquisa. Além disso, consideramos essencial buscar maneiras efetivas de estudar essa dimensão da estratificação no Brasil, já que se trata de uma sociedade reconhecidamente marcada pelas distâncias e hierarquias sociais (Matta, 1979; Freyre, 1961, 1936; Fernandes, 2009; Souza, 2006). Os resultados alcançados neste artigo, como vimos, indicam que, no caso da sociedade brasileira, além de se verificar grande variação e amplitude em termos de status, com uma importante parcela da população em categorias de prestígio muito baixo, as dimensóes social e econômica da estratificação parecem mais entrelaçadas do que em outros países. Tais resultados, sem dúvida alguma, trazem importantes informaçóes sobre as características da hierarquia de status presente no país. Mais evidências, no entanto, são necessárias para interpretarmos esses resultados de modo mais consistente.

Esperamos que este estudo sirva, portanto, de ponto de partida para uma agenda de pesquisa mais ampla, que tenha como meta analisar empiricamente as desigualdades por status no Brasil. Como próximos passos, seria interessante comparar os efeitos de status e classe sobre o comportamento dos indivíduos em termos de estilos de vida e consumo cultural. Caso a nossa escala consiga explicar, de modo mais contundente do que as classes, esse tipo de comportamento, conseguiríamos reforçar a sua interpretação como uma hierarquia de status.

\section{Notas}

1 Os partidos, interessados essencialmente na conquista do poder através do Estado, formariam uma terceira dimensão da estratificação (Weber, 1953).

2 Enquanto o termo "desigualdade" diz respeito à má distribuição de recursos (materiais, culturais, simbólicos etc.), a "estratificação" aponta para a estruturação das desigualdades em classes, grupos de status etc. (Scott e Marshall, 2009). Mais especificamente, a estratificação de uma sociedade poderia ser definida como a sua divisão interna em diferentes categorias, cada uma apresentando chances de vida específicas (Scott, 1996).

3 Max Weber denominava esse processo de social closure.

4 Um exemplo interessante dessas práticas encontra-se na análise de Ribeiro (2008) sobre distância social em contextos de proximidade territorial na cidade do Rio de Janeiro.

5 Os termos Gemeinschaft e Gesellschaft apontam para a diferenciação entre comunidade e sociedade. A primeira, típica de agrupamentos pequenos e economicamente pouco desenvolvidos, se constituiria a partir do sentimento subjetivo dos participantes de pertencer (afetiva ou tradicionalmente) ao mesmo grupo, havendo forte coesão social baseada na força dos laços de proximidade; já a segunda, que aponta para agrupamentos maiores e economicamente mais desenvolvidos, seria formada a partir da união de interesses particulares, havendo maior diferenciação entre os indivíduos, assim como maior liberdade para o estabelecimento de laços sociais. 
6 Para mais detalhes sobre esse tema, ver Scott (1996).

7 Alguns esquemas de classe foram, inclusive, desenvolvidos especialmente para dar conta da estrutura sócio-ocupacional brasileira. É o caso do esquema de Nelson Valle Silva (apud Scalon, 1999), das Categorias Ocupacionais (CATs) elaboradas pelo Observatório das Metrópoles (Ribeiro e Ribeiro, 2013) e também do esquema de inspiraçáo neomarxista criado por Santos (2002).

8 Treiman (1977) desenvolveu uma medida internacional de prestígio, a chamada Siops, através da média do resultado de escalas geradas para aproximadamente sessenta países.

9 Em uma oposição clara à tradição dos estudos de classe, que trabalham com classificaçóes discretas das informações ocupacionais. Sobre as vantagens e desvantagens dessas duas abordagens, ver Ganzeboom, De Graaf e Treiman (1992).

10 Dentro da tradição dos estudos de classe, é importante lembrar que Pierre Bourdieu, em especial em $A$ distinção (2008), busca retomar a ideia weberiana de status. No entanto, ao fazê-lo, reduz o status à dimensão simbólica da divisão por classes.

11 Sobre a história da Cambridge Scale, ver Prandy e Lambert (2003).

12 Ver também Stewart, Prandy e Blackburn (1980) e Prandy (1990).

13 Segundo Prandy e Lambert (2003), os resultados são similares utilizando os dados de amizade ou matrimônio.

14 Posteriormente, alguns estudos passaram a fazer uso de modelos log-lineares. Chan e Goldthorpe (2004), no entanto, argumentam que os resultados são extremamente similares, de modo que não há vantagens em se utilizar tais modelos.

15 No caso do Brasil, o IBGE toma a CBO (Classificação Brasileira de Ocupaçôes) como critério - com modificaçóes pontuais - para classificar as ocupaçóes das PNADs desde 2002.

16 No caso da Inglaterra, por exemplo, foram utilizadas 31 categorias (Chan e Goldthorpe, 2004).

17 Nenhum critério externo, como renda ou escolaridade, foi utilizado nesse processo.

18 É importante lembrar que testes realizados por autores como Prandy e Lambert (2003) já mostraram que os resultados sáo bastante próximos, utilizando-se dados de amizade ou matrimônio.

19 Muito utilizado em estudos sobre segregação espacial, esse índice é uma medida bastante conhecida. O cálculo do mesmo é necessário porque a multidimensional scaling, utilizada posteriormente, toma como input os dados de (dis)similaridade.

20 Nesta análise, utilizamos o modo intervalar de MDSCAL, selecionamos Torgerson como a configuração inicial, indicamos stress convergence e minimum stress em 0.000001, e 1.000 para o máximo de iteraçóes.

21 Para maiores detalhes a respeito dessa técnica, ver Borg, Groenen e Mair (2012).

22 As dimensôes extraídas pela MDSCAL não são necessariamente interpretáveis, podendo apenas refletir variações resultantes de uma série de pequenos efeitos combinados.

23 Correlação significativa ao nível de $p<0,000$.

24 Correlação também significativa ao nível de $p<0,000$.

25 Vide o tradicional sistema Hindu de castas na Índia, onde a segunda casta (Kshatriya) era a dos militares, com a função de proteger a sociedade (Lensky, 1966).

26 É importante lembrar que a maior parte da categoria dos produtores rurais é composta por micro e pequenos produtores.

27 Correlação também significativa ao nível de $p<0,000$.

28 Correlação também significativa ao nível de $p<0,000$.

29 Ao nível de $p<0,000$.

\section{BIBLIOGRAFIA}

BERGMAN, Manfred Max \& JOYE, Dominique. (2001), "Comparing social stratification schemas: Camsis, CSP-CH, Goldthorpe, Isco-88, Treiman, and Wright". Cambridge Studies in Social Research, 9: 1-37

BLAU, Peter M. \& DUNCAN, Otis Dudley. (1967), The American occupational structure. Nova York, Free Press.

BORG, Ingwer; GROENEN, Patrick J. F. \& MAIR, Patrick. (2012), Applied multidimensional scaling. Heidelberg, Springer.

BOURDIEU, Pierre. (2008), A distinção: crítica social do julgamento. São Paulo, Edusp.

CHAN, Tak Wing. (2010), Social status and cultural consumption. Cambridge, Cambridge University Press.

CHAN, Tak Wing \& GOLDTHORPE, John H. (2004), "Is there a status order in contemporary British society? Evidence from the occupational structure of friendship". European Sociological Review, 20 (5): 383-401. 
. (2007), "Class and status: the conceptual distinction and its empirical relevance". American sociological review, 72 (4): 512-532.

DEVINE, Fiona \& SAVAGE, Mike. (2005), "The cultural turn, sociology and class analysis", in F. Devine et al. (orgs.), Rethinking class: culture, identities \& lifestyle, Palgrave Macmillan.

ERIKSON, Robert; GOLDTHORPE, John H. \& PORTOCARERO, Lucienne. (1979), “Intergenerational class mobility in three Western European societies". British Journal of Sociology, 30 (4): 415-441.

FERNANDES, Florestan. (2009), Capitalismo dependente e classes sociais na América Latina. São Paulo, Globo.

FREYRE, Gilberto. (1936), Sobrados e mucambos: decadência do patriarcado rural no Brasil. São Paulo, Companhia Editora Nacional.

. (1961), Casa-grande \& Senzala: formação da familia brasileira sob o regime de economia patriarcal. 2. ed. Rio de Janeiro, José Olympio.

GANZEBOOM, Harry B. G.; DE GRAAF, Paul M. \& TREIMAN, Donald J. (1992), "A standard international socio-economic index of occupational status". Social Science Research, 21 (1): $1-56$.

GOLDTHORPE, John H. (2000), "Social class and the differentiation of employment contracts", in On sociology: numbers, narratives, and the integration of research and theory, Oxford, Oxford University Press.

GOLDTHORPE, John H. \& HOPE, Keith. (1972), "Occupational grading and occupational prestige". Social Science Information/Sur Les Sciences Sociales, 11 (5): 17-73.

GRUSKY, David. (2008), Social stratification. class, race, and gender in sociological perspective. 3. ed. Colorado, Westview Press.

LAUMANN, Edward O. (1973), Bonds of pluralism: the form and substance of urban social networks. Nova York, J. Wiley.

LAUMANN, Edward O. \& GUTTMAN, Louis. (1966), "The relative associational contiguity of occupations in an urban setting". American Sociological Review, 31 (2): 169-178.

LENSKI, Gerhard Emmanuel. (1966), Power and privilege: a theory of social stratification. North
Carolina, UNC Press Books.

MATTA, Roberto da. (1979), Carnavais, malandros e heróis: para uma sociologia do dilema brasileiro. Rio de Janeiro, Rocco.

MARQUES, Eduardo; SCALON, Céli \& OLIVEIRA, Maria Aparecida. (2008), "Comparando estruturas sociais no Rio de Janeiro e em São Paulo." Dados, 51, 1: 215-238.

MARSHALL, Thomas H. (1950), Citizenship and social class. Cambridge (UK), Cambridge University Press.

PRANDY, Kenneth. (1990), "The revised Cambridge scale of occupations". Sociology, 24 (4): 629-655.

PRANDY, Kenneth \& LAMBERT, Paul. (2003), "Marriage, social distance and the social space: an alternative derivation and validation of the Cambridge Scale”. Sociology, 37 (3): 397-411.

PRETECEILLE, Edmond \& RIBEIRO, Luiz Cesar de Queiroz. (1999), "Tendências da segregação social em metrópoles globais e desiguais: Paris e Rio de Janeiro nos anos 80". EURE (Santiago), 25 (76): 79-102.

RIBEIRO, Luiz Cesar de Queiroz. (2008), "Proximidade territorial e distância social: reflexóes sobre o efeito do lugar a partir de um enclave urbano". Revista VeraCidade, 3 (3): 1-21.

RIBEIRO, Carlos Antonio Costa. (2006), "Classe, raça e mobilidade social no Brasil”. Dados, 49 (4): 833-873.

RIBEIRO, Marcelo \& RIBEIRO, Luiz Cesar de Queiroz. (2013), Análise social do território: metodologia para o estudo da estrutura urbana brasileira. Rio de Janeiro, Letra Capital.

RIDGEWAY, Cecilia L. (2013), "Why status matters for inequality". American Sociological Review, XX (X): 1-16.

SANTOS, José Alcides Figueiredo. (2008), "Classe social e desigualdade de gênero no Brasil". Revista de Ciências Sociais, 51 (2): 353-362.

. (2002), Estrutura de posiçóes de classe no Brasil: mapeamento, mudanças e efeitos na renda. Belo Horizonte, Editora UFMG.

SILVA, Nelson Valle. (1974), Posiçâo social das ocupaçôes. Rio de Janeiro, IBGE. (2003), "Os rendimentos pessoais", in C. Hasenbalg e N. V. Silva, Origens e destinos: de- 
sigualdades sociais ao longo da vida. Rio de Janeiro, Topbooks.

SCALON, Maria Céli. (1999), Mobilidade social no Brasil: padröes e tendências. Rio de Janeiro, Revan.

SCOTT, John. (1994), "Class analysis: back to the future”. Sociology, 28 (4): 933-942.

. (1996), Stratification and power: structures of class, status and command. Cambridge, Polity Press.

SCOTT, John \& MARSHALL (2005), Oxford dictionary of sociology. Oxford, Oxford University Press.

SOUZA, Jessé. (2006), A construção social da subcidadania: para uma sociologia política da modernidade periférica. Belo Horizonte, Editora UFMG.

STEWART, Alexander; PRANDY, Kenneth e BLACKBURN, Robert Martin. (1973), "Measuring the class structure". Nature, 245 (5426): 415-417.

(1980), Social stratification and occupations. Londres, Macmillan.

TÖNNIES, Ferdinand. (1953 [1931]), "Estates and classes", in R. Bendix e S. M. Lipset (eds.), Class status and power, Glencoe, Free Press.

TREIMAN, Donald J. (1977), Occupational prestige in comparative perspective. Nova York, New York Academic Press.

WARNER, W. Lord \& LUNT, Paul Sanborn. (1942), The status system of a modern community. New Haven, Yale University Press.

WEBER, Max. (1953), "Class, Status and Power", in R. Bendix e S. M. Lipset (eds.), Class, status and power: a reader in social stratification, Glencoe, Free Press.

WEEDEN, Kim A. \& GRUSKY, David B. (2004), "Are there any big classes at all?". Research in Social Stratification and Mobility, 22: 3-56.

WRIGHT, Erik Olin. (1989), The debate on classes. Londres, Verso. 


\section{UMA NOVA ABORDAGEM EMPÍRICA PARA A HIERARQUIA DE STATUS NO BRASIL}

\author{
André Ricardo Salata
}

Palavras-chave: Status; Escala; Estratificação; Desigualdades; Distâncias sociais.

Uma das características mais importantes das análises de Max Weber a respeito das desigualdades é a conhecida separação entre classe econômica e status social como duas dimensóes distintas da estratificação. O presente trabalho tem como objetivo, então, verificar se no Brasil atualmente poderíamos identificar uma hierarquia de status bem definida, e quais seriam suas características. Para tanto, serão utilizados os dados da Pesquisa Nacional por Amostra de Domicílios (2013), através dos quais - utilizando a técnica de multidimensional scaling-, trabalharemos as informaçóes cruzadas referentes às categorias ocupacionais de chefes de domicílio e seus cônjuges. Como resultado da análise, teremos uma escala de proximidades e distâncias sociais, que será apresentada, analisada e, também, discutida a sua validade enquanto indicadora de status.

\section{A NEW EMPIRICAL APPROACH FOR THE STATUS HIERARCHY IN BRAZIL}

\section{André Ricardo Salata}

Keywords: Status; Scale; Stratification; Inequality; Social distances.

One of the most important features of Max Weber's analyzes about inequality is the known distinction between economic class and social status as two separate dimensions of stratification. The present paper, then, aims to verify if in contemporary Brazil we could identify a well-defined status hierarchy. Data from the National Household Survey (2013) will be used, through which - applying the multidimensional scaling technique -, we will work cross information concerning occupational categories of heads of households and their partners. As a result, we will have a range of social proximities and distances, to be presented, analyzed and also discuss the validity of its interpretation as a status indicator.

\section{A NOUVELLE APPROCHE EMPIRIQUE DE PRESTIGE HIERARCHIE AU BRESIL}

\author{
André Ricardo Salata
}

Mots-clés: Prestige; Echelle; Stratification; Les Inégalités; Distances sociales.

Une des caractéristiques les plus importantes des analyses de Max Weber des inégalités est la séparation entre la classe économique et le prestige social comme deux dimensions distinctes de la stratification. Ce document vise à vérifier puis au Brésil on pourrait identifier une hiérarchie de statut bien défini, et quelles sont ses caractéristiques. À cette fin, les données de l'Enquête Nationale par Sondage seront Utilisés (2013), par laquelle - en utilisant la technique de multidimensional scaling - nous allons travailler les informations croix concernant les catégories professionnelles de chefs de ménage et de leurs conjoints. À la suite de l'analyse, nous avons une gamme de proximités et distances sociales, qui seront présentés, analysés et discuté sa validité en tant qu'indicateur de prestige. 